\title{
Pvt1 Oncogene Long Non-Coding RNA
}

National Cancer Institute

\section{Source}

National Cancer Institute. Pvt1 Oncogene Long Non-Coding RNA. NCI Thesaurus. Code C18601.

Pvt1 oncogene long non-coding RNA ( 2 kb) is encoded by the human PVT1 gene. This long non-coding RNA may play a role in the positive regulation of MYC gene expression. 